\title{
A LETHAL ALLELE OF DILUTE IN THE HOUSE MOUSE
}

\author{
A. G. SEARLE
}

University College, London, W.C.I.

Received 12.ii. 52

ThE recessive gene "dilute lethal" (symbol $d^{l}$ ) first occurred in the pure line $\mathrm{C}_{57} \mathrm{BL} / \mathrm{Gr}$ in June 1950 , as a spontaneous mutation. It was noticed that three out of a litter of seven had a dilute fur-colour. Later they developed neurological defects and died soon after weaning. The parents were perfectly normal in behaviour and fur-colour.

\section{DESCRIPTION}

On a $\mathrm{C}_{57}$ Black background the mutants can first be distinguished at the age of three or four days by their lighter pigmentation. For the first nine days or so they behave normally and start walking. But soon they tend to overbalance. If at rest they lean over more and more to one side or the other until they fall, with an associated hyperextension of the limbs on the opposite side. On righting themselves, nine-day mutants may show slight convulsive limb movements. When walking they topple over without warning and the hind-limbs tend to drag.

At twelve days, the mutant is hardly able to walk at all, but can move more easily when on its side, often going in circles in apparent efforts to right itself, which take much longer than normal. Convulsions are more marked, being clonic in nature with the fore-limbs rapidly beating up and down.

By fifteen or sixteen days the whole syndrome is well-developed. A fit usually begins whenever the animal is disturbed or when it overbalances and struggles to right itself, but sometimes the cause is uncertain. Following loss of balance, the convulsive seizures start as a rule when an upright posture is regained. Opisthotonus soon sets in, with an arching upwards of head and tail to such an extent that they often meet each other. The forepaws are characteristically brought up on each side of the nose. Then the animal often overbalances; violent righting movements are made and another fit may be precipitated.

Later, when the symptoms become more severe, the hind-limbs become increasingly involved and the mutant makes violent bouncing movements. Limb convulsions associated with the opisthotonus may become tetanic, with the animal staying rigid for a second or two. When upright, it can at best make weak lurching movements, although it is more active when on its side. Sometimes it is found lying on its back in the cage and it will eat in this position. If food and water are placed within reach it can eat and drink normally. Hyperacuity is 395 
sometimes shown, but on other occasions the same animal shows no reaction to a loud noise.

The plate shows characteristic postures adopted by mutants during and after convulsive fits. When an affected mouse is in the nest it can subdue its limb convulsions somewhat by clutching on to straws, etc.;

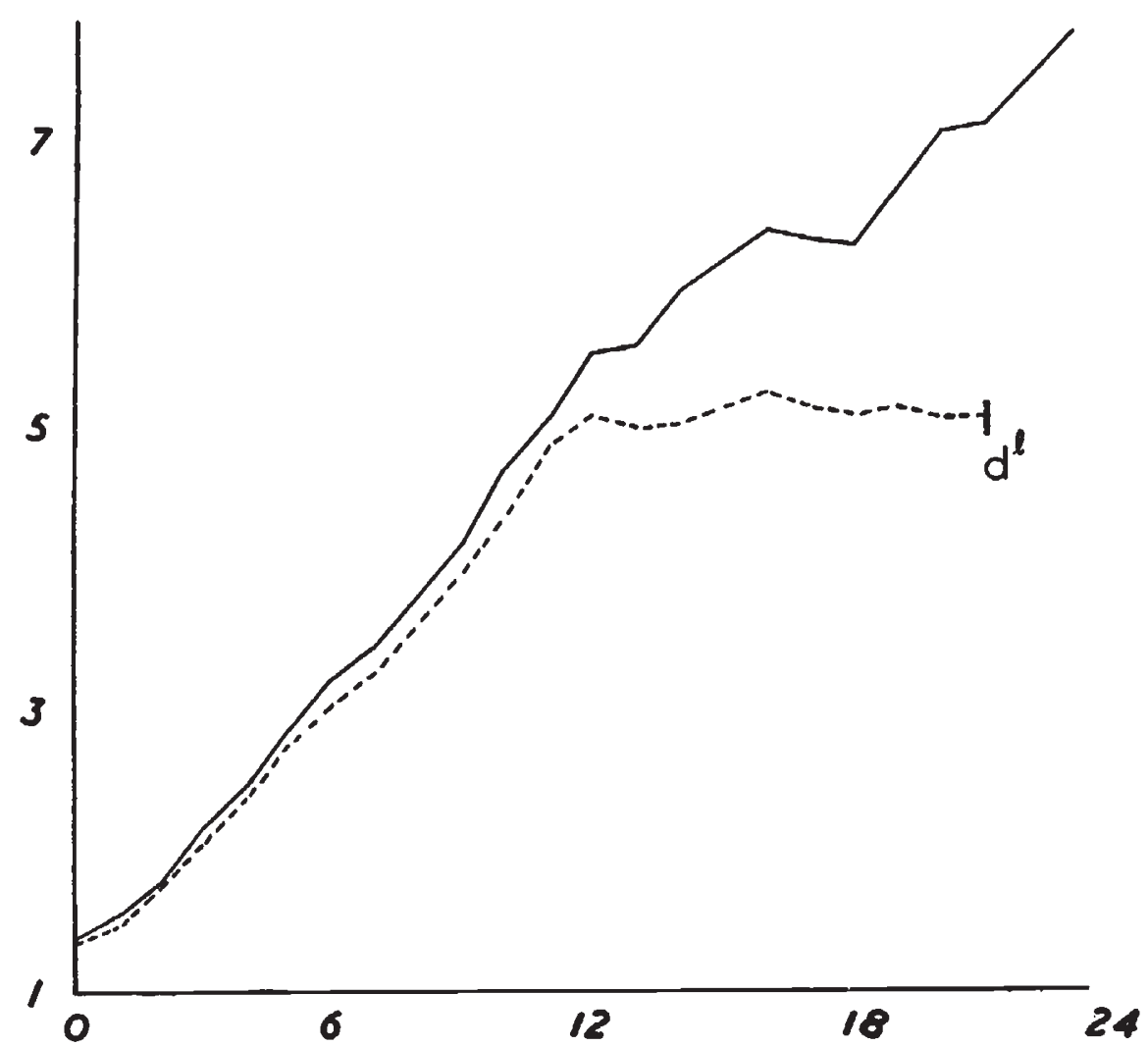

Frg. x.-Mean daily weights of four $d^{l}$ and four normal litter-mates compared.

limb movements are generally less violent than when on a smooth surface.

Death ensues at about three weeks, preceded by great weakness and emaciation. Mutants have been kept alive for over a fortnight longer by transfer to a foster-mother before the age of weaning or by leaving plenty of wet food within easy reach. But the dilute lethals roll helplessly in the wet mash so that their fur is soon matted and foul.

\section{WEIGHT}

There was no significant difference in the birth-weights of normal and mutant, the mean weights of forty-nine normals being $\mathrm{I} \cdot 4 \mathrm{I} \pm 0.03$ grams and of twenty-nine mutant litter-mates $I \cdot 45 \pm 0 \cdot 04$ grams. At eleven days, normals were heavier on the average $-4 \cdot 98 \pm 0.12$ grams against $4 \cdot 60 \pm 0.22$ grams for $d^{2}$-but the difference was not quite sig- 
nificant $(\mathrm{t}=\mathrm{I} \cdot 73, \mathrm{n}=32$ and $\mathrm{o} \cdot \mathrm{I}>\mathrm{P}>0 \cdot 05)$. From twelve days on, growth-curves of lethal and normal diverge rapidly, as figs. I and 2 show. The weights of affected animals may remain fairly stationary, as in fig. I, or they may rise slowly and then fall rapidly, as fig. 2 shows. The falling-off from the normal growth pattern is presumably due to

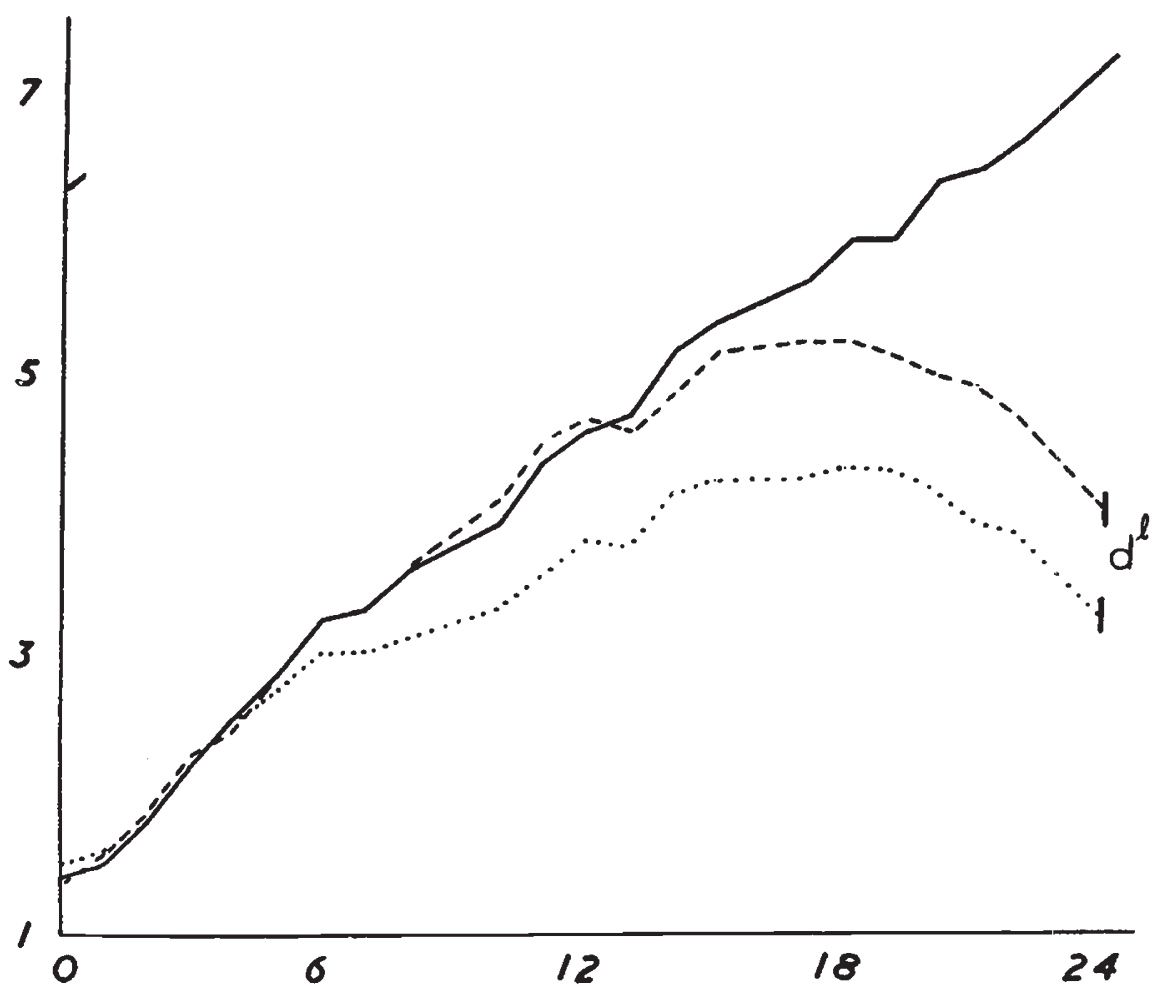

Fig. 2.--Individual growth-curves of two dilute lethals compared with the mean growthcurve for five normal litter-mates.

the great difficulty with which the mutants move around to reach food and water.

\section{HAIR}

The action of $d^{l}$ has been observed on a black, brown and yellow background. It dilutes all these fur-colours to the same extent as Maltese dilution $(d)$ : normal dilute black and brown mice have been observed in the same litters as the corresponding dilute lethals and appear identical in colour.

Preparations of $d^{l}$ hairs have been made by the method of E. S. Russell (1946). As in $d$ hairs (Russell, 1949) there is intracellular clumping of pigment granules and irregularities of pigment distribution in and near the root-bulb, shown in fig. 3 .

In black hair (fig. 4), the individual granules in medullary cells cannot be distinguished. The medullary cells of both $d$ and $d^{l}$ mice 
are very irregular and in both there has been some intercellular deposition of pigment to form very large clumps, as described by Russell (1949) for Maltese dilution. Cortical granules are lacking in the section of $d^{l}$ hair shown, but this is not true for the whole length of the hair. But the numbers of cortical granules in equivalent regions of hairs of each dilute genotype have not been compared in actual counts.

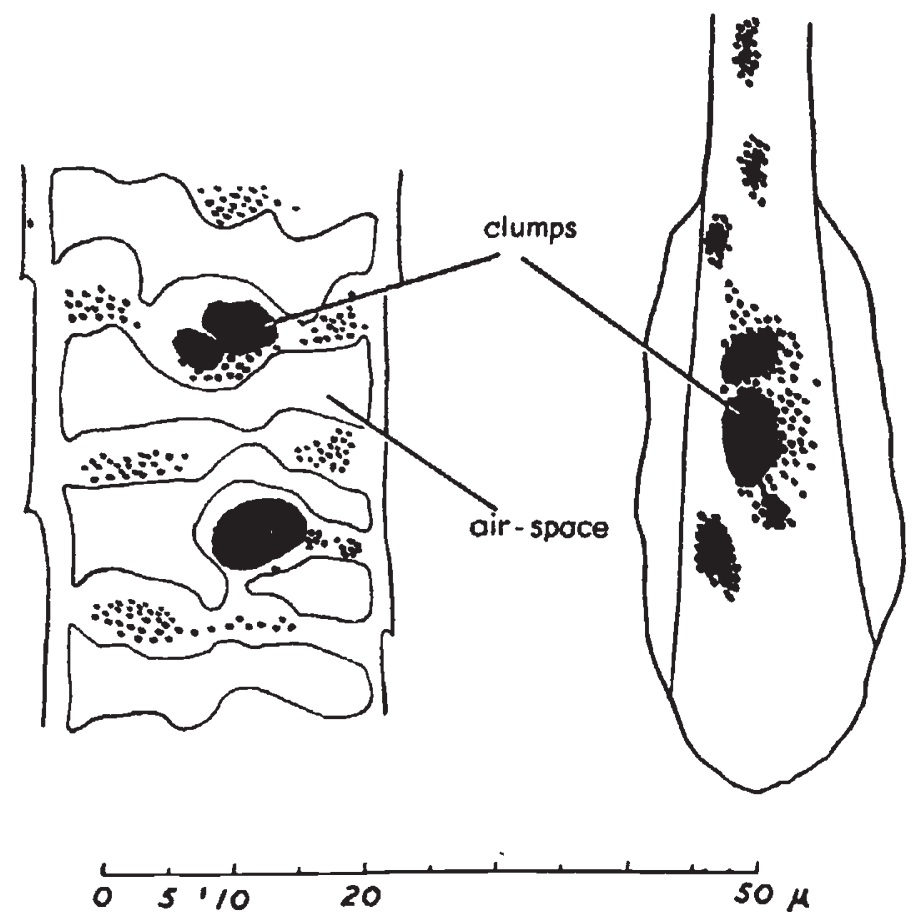

Fig. 3.-Dilute lethal yellow hair, showing intracellular pigment clumps and irregular distribution of pigment in the root. Camera lucida drawing.

\section{OTHER INVESTIGATIONS}

Under the age of ten days there was no difference in the response of normals and mutants to position change, when suspended by the tail. In both there was dorsiflexion of the spine, raising of the head and protraction and extension of the fore-limbs. Later, however, the lethal tends to start a convulsive fit when held in this position. Mutants over a fortnight old, which are almost completely incapable of voluntary movement on land, are nevertheless able to swim vigorously. But instead of making straight for the shore, like normals, they tend to go round in circles, recalling their motion when on their sides on land. No abnormalities of the inner ear were found when a histological examination of this organ was made.

An examination of brain sections has revealed no gross defects. In particular, the cerebellum appears to be structurally similar to that of a normal litter-mate, with all its cell-layers intact. 


\section{Black hair}

\section{dilute lethal}

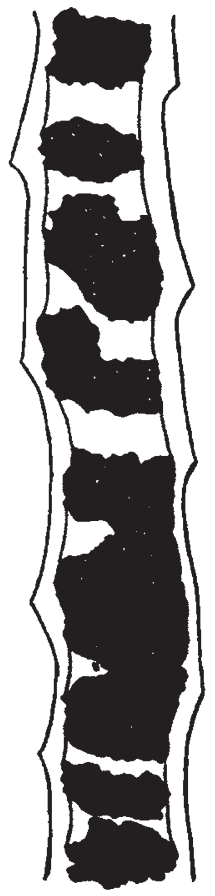

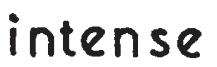

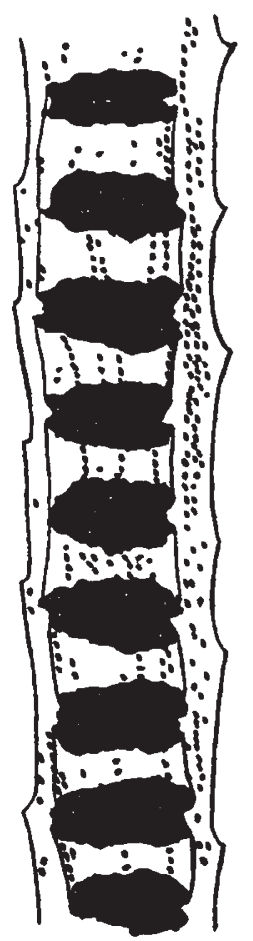

Maltese dilute

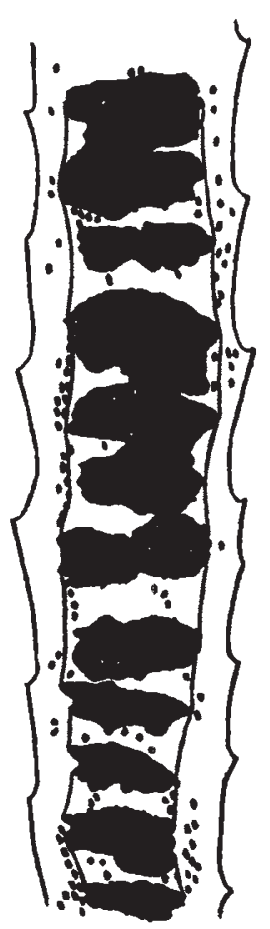

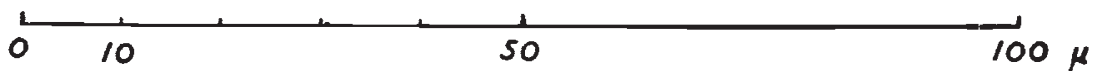

Frg. 4.-Black hair, showing intercellular pigment clumps and irregularity of cells in $d$ and $d^{l}$. Camera lucida drawing.

\section{SEGREGATION}

In $\mathrm{C}_{57}$ Black sibships segregating for $d^{l}$ and containing fifteen or more classifiable young, the ratio of normals to mutants was $130: 34$, or 20.7 per cent $d^{l}$. Disregarding the slight degree of selection in these data, one would expect $25^{\circ}$ o per cent recessives; the observed ratio was in reasonable agreement with this expectation $\left(\chi^{2}=I^{\bullet} 59, n=1\right.$ and $\mathrm{P}=\mathbf{0} \cdot 2 \mathrm{I}$ ).

Because of the close resemblance of the mutant's hair to that of a Maltese dilute phenotype, the gene was tested for allelomorphism against 
dilute and its mimic leaden. None out of twenty-nine offspring from the matings of known heterozygotes to leaden females had diluted furcolour. But of sixty-five offspring from the matings to short-ear dilute females, thirty-five, or 54 per cent, had a diluted fur-colour, in agreement with the I : I ratio expected with allelomorphism.

The $F_{1}$ dilutes were very fertile and perfectly normal in behaviour. They were mated together in pairs, producing 28I offspring. All of these, classified when a few days old, had dilute fur-colour.

These rcsults strongly suggest genuine allelomorphism, though they do not, of course, entirely rule out the possibility that $d$ and $d^{l}$ are pseudo-alleles (Glass, r 949 ). If the two genes do in fact occupy different loci, the upper limit of recombination (on the 5 per cent level of significance) is $I \cdot I$ per cent.

The three $F_{2}$ phenotypes were found in the ratio 59 short-eared dilutes $($ se $d /$ se $d)$ : I 6 long-eared dilutes $\left(\right.$ se $\left.d /+d^{2}\right)$ : 70 dilute lethals $\left(+d^{l} /+d^{l}\right)$. The loci for se and $d$ are only $0^{\cdot} \cdot 2 \mathrm{cM}$. apart (Castle et al., I936) so all the animals in each phenotype group can fairly safely be assigned to the genotypes given in brackets. The observed ratio does not differ significantly from the $\mathrm{I}: 2:$ I ratio expected $\left(\chi^{2}=\mathrm{I} \cdot 7, \mathrm{n}=2\right.$ and $\mathbf{P}=\mathbf{0} \cdot 4$ ). Sex-ratios differed little from equality.

The juxtaposition of se and $d$ loci allows dilute lethal to be kept as a balanced stock, $s e+1+d^{l}$, in which practically all long-eared intense mice are of this genotype and are used to produce the next generation.

\section{DISCUSSION}

The pattern of behaviour of dilute lethals has some features in common with other neurological mutants in the mouse. Jittery mice (DeOme, 1945) show a marked lack of muscular co-ordination, with frequent over-balancing and lurching movements. Later they have convulsive fits; they also appear to suffer from opisthotonus when they fall on their sides, for they tend to support themselves on their head and tail. Harman (1950) found polycystic alterations in the white matter of the brain of this mutant.

Young Trembler mice (Falconer, I95I), when stimulated, suffer from convulsive fits in which there is some opisthotonus, and occasional vigorous up and down movements of the fore-limbs. But the characteristic rapid trembling movements of head and neck in the adult and the hyperextension of the limbs found throughout life have no counterpart in dilute lethal. With due precautions, most Tremblers pass out of their critical convulsive stage and reach adult life. But even in those dilute lethals which survived to five weeks there was no sign of any abatement in the severity of the symptoms.

Castle, Gates, Reed and Law (1936) have presented evidence to show that $d$ is associated with an increased body-weight of about 2 per cent when compared with intcnse litter-mates, as well as associated changes in tail-length, etc. No attempt has yet been made to see if the compound $d / d^{l}$ has a similar effect. Since se reduces adult size (Law, 

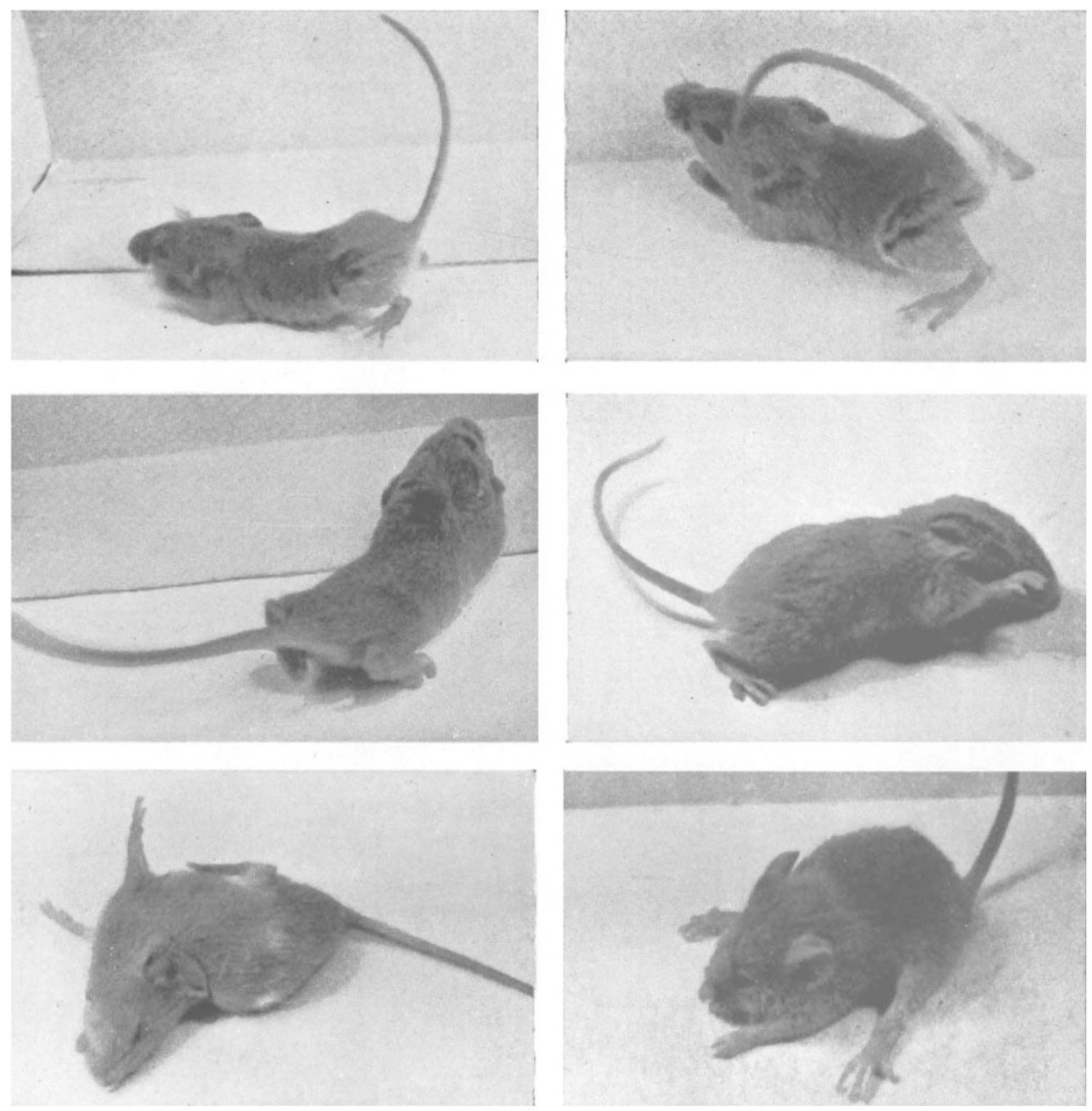

PrATE-Dilute lethal's behaviour. $a$ and $\mathrm{b}$, Typical postures during fit, with marked opisthotonus and fore-limbs beating up and down. c, Hind-limbs involved in convulsions, with bouncing movement. $d$, Later stage, no opisthotonus. $e$, Lying on side and attempting to right itself. $f$, Huddled-up posture after fit. 
1938) one would not be able to use this gene as a marker and the genotypes of the dilute animals would have to be found by progeny tests.

This mutant adds another item to the now lengthy list of pleiotropic genes in the mouse with major effects besides those on fur-colour. In none of these has the connexion between the colour changes and other effects been elucidated. Other members of the group with pleiotropic neurological effects are pallid and varitint-waddler. The former dilutes fur- and eye-colour and also often leads to absence of otoliths (Lyon, I95I); the latter combines spotting and dilution with circling, head-tossing and deafness, also epileptiform fits in the homozygote (Cloudman and Bunker, r945).

\section{SUMMARY}

I. Dilute lethal (symbol $d^{l}$ ) is a new recessive mutation in the mouse. Affected animals suffer from neurological symptoms, which include clonic convulsions with opisthotonus and ataxia, which lead to death soon after weaning.

2. Evidence is presented to show that this gene is an allele of Maltese dilution.

Acknowledgments.-I am indebted to Dr H. Grüneberg for invaluable advice and criticism and to Dr C. A. B. Smith for statistical assistance. I should also like to thank Mr A. Munday for help with the photography. This work was carried out during the tenure of an Agricultural Research Council research studentship.

\section{REFERENCES}

CASTLE, W. E., GATES, W. H., REED, S. G., AND LAW, L. W. 1936. Studies of a size cross in mice. II. Genetics, 21, 310-323.

CASTLE, W. E., GATES, W. H., REED, S. G., AND SNELL, G. D. 1936. Identical twins in a mouse cross. Science, $84,5^{81}$.

GLOUdMAN, A. M., AND BUNKER, L. E. 1945. The varitint-waddler mouse. A dominant mutation in Mus musculus. 7. Hered., 36, 259-263.

DEOME, к. в. 1945. A new recessive lethal mutation in mice. Univ. Calif. Publ. Zool., $53,4 \mathrm{I}-66$.

FALCONER, D. S. 1951. Two new mutants, "Trembler" and " reeler", in the house mouse (Mus musculus L.). 7. Genet., 50, 192-201.

GLAss, B. 1949. The genes and gene action. In Survey of Biological Progress, Volume I. 396 pp. New York : Academic Press.

HARMAN, P. J. 1950. Polycystic alterations in the white matter of the brain of the "jittery" mouse. Anat. Rec., 106, 304 .

LAW, L. W. 1938. Studies in size inheritance in mice. Genetics, 23, 399-422.

LYON, M. F. I95I. Hereditary absence of otoliths in the house mouse. F. Physiol., I I4, $410-418$.

RUSSELL, E. S. 1946. A quantative histological study of the pigment found in the coatcolour mutants of the house mouse. I. Variable attributes of the pigment granules. Genetics, 3I, 327-346.

RUSSELL, E. S. 1949. ibid. IV. The nature of the effects of genic substitution in the five major allelic series. Genetics, 34, 146-166.

Note added in proof.-W. L. Russell, in his paper "X-ray-induced mutations in mice" (Cold Spr. Harb. Sym. quant. Biol. I951. 16, 327-336) reports the occurence of two induced and one spontaneous mutation at the $D$ locus, which seems to be indistinguishable from dilute lethal, both in their action on fur and on behaviour. 